\title{
Diphtheria, Pertussis, Poliomyelitis, Tetanus, and Haemophilus influenzae Type b Vaccinations and Risk of Eczema and Recurrent Wheeze in the First Year of Life: The KOALA Birth Cohort Study
}

Citation for published version (APA):

Kummeling, I., Thijs, C., Stelma, F., Huber, M., van den Brandt, P. A., \& Dagnelie, P. C. (2007).

Diphtheria, Pertussis, Poliomyelitis, Tetanus, and Haemophilus influenzae Type b Vaccinations and Risk of Eczema and Recurrent Wheeze in the First Year of Life: The KOALA Birth Cohort Study. Pediatrics, 119(2), e367-373. https://doi.org/10.1542/peds.2006-1479

Document status and date:

Published: 01/01/2007

DOI:

10.1542/peds.2006-1479

Document Version:

Publisher's PDF, also known as Version of record

Please check the document version of this publication:

- A submitted manuscript is the version of the article upon submission and before peer-review. There can be important differences between the submitted version and the official published version of record. People interested in the research are advised to contact the author for the final version of the publication, or visit the DOI to the publisher's website.

- The final author version and the galley proof are versions of the publication after peer review.

- The final published version features the final layout of the paper including the volume, issue and page numbers.

Link to publication

\footnotetext{
General rights rights.

- You may freely distribute the URL identifying the publication in the public portal. please follow below link for the End User Agreement:

www.umlib.nl/taverne-license

Take down policy

If you believe that this document breaches copyright please contact us at:

repository@maastrichtuniversity.nl

providing details and we will investigate your claim.
}

Copyright and moral rights for the publications made accessible in the public portal are retained by the authors and/or other copyright owners and it is a condition of accessing publications that users recognise and abide by the legal requirements associated with these

- Users may download and print one copy of any publication from the public portal for the purpose of private study or research.

- You may not further distribute the material or use it for any profit-making activity or commercial gain

If the publication is distributed under the terms of Article $25 \mathrm{fa}$ of the Dutch Copyright Act, indicated by the "Taverne" license above,

Download date: 26 Apr. 2023 


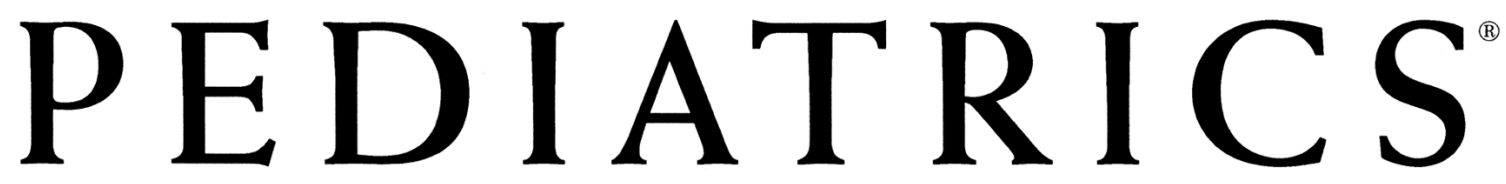

OFFICIAL JOURNAL OF THE AMERICAN ACADEMY OF PEDIATRICS

\section{Diphtheria, Pertussis, Poliomyelitis, Tetanus, and Haemophilus influenzae Type b Vaccinations and Risk of Eczema and Recurrent Wheeze in the First Year of Life: The KOALA Birth Cohort Study}

Ischa Kummeling, Carel Thijs, Foekje Stelma, Macheld Huber, Piet A. van den Brandt and Pieter C. Dagnelie

Pediatrics 2007;119; e367-e373

DOI: $10.1542 /$ peds.2006-1479

The online version of this article, along with updated information and services, is located on the World Wide Web at:

http://www.pediatrics.org/cgi/content/full/119/2/e367

PEDIATRICS is the official journal of the American Academy of Pediatrics. A monthly publication, it has been published continuously since 1948. PEDIATRICS is owned, published, and trademarked by the American Academy of Pediatrics, 141 Northwest Point Boulevard, Elk Grove Village, Illinois, 60007. Copyright @ 2007 by the American Academy of Pediatrics. All rights reserved. Print ISSN: 0031-4005. Online ISSN: 1098-4275.

\section{American Academy of Pediatrics}




\title{
Diphtheria, Pertussis, Poliomyelitis, Tetanus, and Haemophilus influenzae Type b Vaccinations and Risk of Eczema and Recurrent Wheeze in the First Year of Life: The KOALA Birth Cohort Study
}

\author{
Ischa Kummeling, MSc ${ }^{a}$, Carel Thijs, MD, PhDa, Foekje Stelma, MD, PhD ${ }^{b}$, Macheld Huber, MDc, Piet A. van den Brandt, PhD ${ }^{a}$ \\ Pieter C. Dagnelie, PhDa
}

aDepartment of Epidemiology, Maastricht University, Maastricht, Netherlands; bDepartment of Medical Microbiology, University Hospital of Maastricht, Maastricht, Netherlands; ‘ Louis Bolk Institute, Driebergen, Netherlands

The authors have indicated they have no financial relationships relevant to this article to disclose.

\begin{abstract}
OBJECTIVES. Among potential etiologic factors for atopic manifestations, infant vaccinations have recently been discussed. We evaluated in a prospective design whether infants who were unvaccinated or vaccinated according to incomplete vaccination schedules in the first 6 months of age were at decreased risk for eczema and recurrent wheeze in the first year of life.
\end{abstract}

METHODS. Information on vaccinations against diphtheria, pertussis, poliomyelitis, tetanus; Haemophilus influenzae type b vaccine; and eczema and recurrent wheeze was collected by repeated questionnaires in 2764 families participating in the KOALA Birth Cohort Study in the Netherlands. A standard vaccination schedule referred to 3 diphtheria, pertussis, poliomyelitis, tetanus, and Haemophilus influenzae type $\mathrm{b}$ vaccinations in the first 6 months with the first given in months 1 to 3; an incomplete vaccination schedule was defined as any other vaccination schedule. Exclusion criteria were prematurity (gestational age $<37$ weeks) and congenital abnormalities related to immunity (such as Down syndrome). Multiple logistic regression models were fitted to adjust for confounding factors.

RESULTS. During the first year of life, the incidence of eczema was 23\% (584 of 2537 infants) and of recurrent wheeze, the incidence was 8.5\% (203 of 2402 infants). At age 6 months, $1969(77 \%)$ of 2545 infants had been vaccinated according to a standard schedule, $393(15 \%)$ vaccinated according to an incomplete schedule, and $182(7 \%)$ never vaccinated. Compared with infants with standard vaccination schedules, infants with incomplete schedules did not differ significantly in eczema risk or recurrent wheeze. This was also true for infants who had never been vaccinated.

Www.pediatrics.org/cgi/doi/10.1542/
peds.2006-1479
doi:10.1542/peds.2006-1479
Key Words
vaccinations, birth cohort, infants, eczema,
recurrent wheeze
Abbreviations
DPPT_-diphtheria, pertussis,
poliomyelitis, tetanus
Hib-Haemophilus influenzae type b
ETS-environmental tobacco smoke
OR-odds ratio
CI-confidence interval
IgE-immunoglobulin E
DPT_-diphtheria, pertussis, tetanus
Accepted for publication Aug 16, 2006
Address correspondence to Ischa Kummeling,
MSc, Department of Epidemiology, Care and
Public Health Research Institute, Maastricht
University, PO Box 616, 6200 MD, Maastricht,
Netherlands. E-mail: ischa.kummeling@epid.
unimaas.nl
PEDIATRICS (ISSN Numbers: Print, 0031-4005;
Online, 1098-4275). Copyright $\odot 2007$ by the
American Academy of Pediatrics


CONCLUSION. This study shows that the risk of eczema or recurrent wheeze at 1 year of age does not differ between infants with different vaccination status at the age of 6 months.

A TOPIC ECZEMA IS the most common atopic disease in infancy, affecting up to one third of children in Western societies. ${ }^{1}$ The presence of atopic eczema has been reported to be associated with an increased risk of wheeze and asthma later in life. ${ }^{2}$

Among potential etiologic factors, vaccinations have recently been discussed. Two mechanisms have been proposed by which vaccinations could affect the development of atopic disease: they may have direct allergyinducing immune effects or prevent possible protective effects of natural infections.,4 Epidemiologic evidence for an association between vaccinations and atopy development is inconsistent. ${ }^{4-26}$ Some caution is needed, because some studies were hampered by small numbers of unvaccinated children, and some others were crosssectional, in which, by design, the possibility of reverse causation exists. Also, the possibility of confounding by contraindication is a concern in interpreting results. Motives for not vaccinating are likely to be health related, which may result in confounding by contraindication if these health-related problems are associated with atopic disease but are not usually described in these studies. ${ }^{27}$

The prospective KOALA Birth Cohort Study in the Netherlands includes a large proportion of infants who are completely unvaccinated $(n=182[7 \%])$ at age 6 months, because their parents opted for deviating from the recommended vaccination schedule. KOALA is (in Dutch) an acronym for Child, Parent and Health: Lifestyle and Genetic Constitution. The present report prospectively evaluates whether infants who were unvaccinated or vaccinated according to an incomplete vaccination schedule in the first 6 months of age were at decreased risk for eczema or recurrent wheeze in the first year of life compared with infants who were completely vaccinated. We also present parental motives for deviating from the standard vaccination schedule.

\section{METHODS}

\section{Study Population}

The KOALA Birth Cohort Study started in October $2000 .{ }^{28}$ Participants were recruited in the southern provinces of the Netherlands from 2 sources. First, healthy pregnant women at 34 weeks of gestation participating in the Pregnancy-Related Pelvic Girdle Pain Study, a cohort study, ${ }^{29}$ were asked to participate in the KOALA Study ("conventional subcohort"). These women had been recruited through midwife practices at 12 to 16 weeks of gestation (and were, therefore, not selected on the basis of pelvic pain symptoms). Second, pregnant women with so-called "alternative" lifestyles were recruited through several specific recruitment channels, that is, anthroposophic doctors and midwives, anthroposophic under-5 clinics, Steiner schools, posters and flyers in organic food shops, and magazines for special interest groups (eg, homeopathy, anthroposophy, and antivaccine; "alternative subcohort"). Anthroposophy is a human-oriented spiritual philosophy grounded by Rudolf Steiner with specific theories and practices on health, education, art, architecture, and "biodynamic" agriculture. A total of 2834 participants were included in the KOALA study, of whom 2343 were found through the Pregnancy-Related Pelvic Girdle Pain Study and 491 through the specific recruitment channels. Exclusion criteria in the present study were prematurity (gestational age $<37$ weeks) and congenital abnormalities related to immunity (such as Down syndrome). The study was approved by the Medical Ethical Committee of University Maastricht/Academic Hospital Maastricht. All of the participants had signed informed consent and completed the first questionnaire at the third trimester of pregnancy.

\section{Exposure and Follow-up}

In the Netherlands, during the time of the study, infants in their first 6 months were vaccinated against diphtheria, pertussis (with whole cell pertussis vaccine), poliomyelitis, tetanus (DPPT) and Haemophilus influenzae type b (Hib) at 2, 3, and 4 months of age. More specifically, before March 2003, this concerned a combined DPPT vaccination and a separate Hib vaccination given simultaneously. From March 2003 onward, a combined DPPT-Hib vaccination was given. In this study, the combined diphtheria/pertussis/tetanus/polio vaccination with a separate Hib vaccination (as used before March 2003) was considered as 1 DPPT-Hib vaccination at the same time and is called "DTTP-Hib." A minority of Dutch parents opt for deviating from the standard vaccination schedule and, for example, omit the pertussis component from the DPPT vaccine or postpone the first vaccinations to a later age; some even refrain from all vaccinations.

Vaccinations in the first 6 months of life were assessed by questionnaire when the infants were 7 months of age. The questions were phrased as follows: "Until now, has your child received the standard vaccinations?" (namely DTTP-Hib vaccinations at 2, 3, and 4 months). Answering options were as follows: (1) yes; (2) no, my infant received vaccinations but according to another vaccination schedule; or (3) no, my infant received no vaccinations. Then, the age of the first vaccination was asked for. We divided infants in 3 groups: (1) vaccinated according to a standard schedule (standard DPPT-Hib vaccinations, the first vaccination given in months $1-3$ ); (2) vaccinated according to an incomplete schedule (any other schedule); or (3) never vaccinated until the age of 
6 months. Infants were regarded as vaccinated if they had been vaccinated at least once. We verified the parental reported history of vaccinations in a random sample of 300 subjects from the alternative subcohort by retrieving their vaccination records at the Dutch Vaccination Administration Office. Using these records, a medical student who was blinded for the parentally reported vaccination data determined by which vaccination schedule the infants had been vaccinated. A total of $73 \%$ of infants could be found in the records of the Dutch Vaccination Administration Office, and the parental reported history was similar to the information in the medical charts in $89 \%$ of these cases (notably, all 78 infants who were not vaccinated according to the parental report were not vaccinated according to the vaccination records either, and 86 [91\%] of 94 case subjects who were standard vaccinated according to parents were confirmed by the vaccination records).

Eczema development in the first year was assessed by questionnaire. At ages 7 and 12 months, parents were asked whether their child had ever had an itchy rash that was coming and going in the past months. If this question was answered affirmatively at least once, infants were classified as having developed eczema in the first year of life. Infants for whom only diaper rash, rash around the eyes, and/or scalp scaling was reported were not regarded as having developed eczema. Wheeze was also asked for in the 7- and 12-month postpartum questionnaires. At ages 7 and 12 months, parents were asked whether their child ever had showed symptoms of wheeze and how many attacks in the past months. "Recurrent wheeze" was defined as a reported presence of wheezing with $\geq 4$ attacks ever in the first year.

\section{Statistical Analysis}

Missing data in the questionnaires were treated as missing in the analyses and are presented as "unknown" in the tables. Multiple logistic regression analyses were used to adjust for potential confounders by simultaneously including the following covariates in the regression models (all for the first 6 months of life and defined as in Table 1): gender; $\geq 1$ self-reported doctor's diagnoses of parental or siblings' atopic manifestations such as asthma, pet or house dust mite allergy, hay fever, eczema, and/or food allergy; number of older siblings; breastfeeding duration; attending day care facilities; pets; exposure to environmental tobacco smoke (ETS); antibiotics use by mother during lactation; and oral antibiotic use of infant.

Because some previous studies indicated that associations between exposures and atopic outcomes were limited to groups with increased inherited propensity for developing atopic disease, ${ }^{30,31}$ we first tested the possibility of an interaction between vaccination status and parental or sibling's history of atopy. Because none of these interaction terms were statistically significant, they
TABLE 1 Characteristics of the Study Population for the Total Cohort, Stratified by Subcohort

\begin{tabular}{|c|c|c|}
\hline \multirow[t]{2}{*}{ Characteristic } & \multicolumn{2}{|c|}{$\begin{array}{l}\text { Total Cohort } \\
(N=2764)\end{array}$} \\
\hline & $N$ & $\%^{\mathrm{a}}$ \\
\hline Male & 1410 & 51.0 \\
\hline \multicolumn{3}{|l|}{ Parental history of atopic manifestations } \\
\hline None & 1339 & 48.4 \\
\hline Father & 519 & 18.8 \\
\hline Mother & 604 & 21.9 \\
\hline Both & 302 & 10.9 \\
\hline \multicolumn{3}{|l|}{ Sibling history of atopic manifestations } \\
\hline No siblings & 1155 & 43.7 \\
\hline 1 sibling, not atopic & 833 & 31.5 \\
\hline 1 sibling, atopic & 261 & 9.9 \\
\hline$\geq 2$ siblings, not atopic & 235 & 8.9 \\
\hline$\geq 2$ siblings, one or both atopic & 159 & 6.0 \\
\hline Unknown & 121 & \\
\hline \multicolumn{3}{|l|}{ Breastfeeding at 6 mo of age } \\
\hline Yes, months 1-4 exclusive BF & 622 & 24.6 \\
\hline Yes, months 1-4 nonexclusive BF & 441 & 17.4 \\
\hline No, months $1-4$ exclusive BF & 62 & 2.4 \\
\hline No, months $1-4$ nonexclusive & 996 & 39.4 \\
\hline Never breastfeeding & 410 & 16.2 \\
\hline Unknown & 233 & \\
\hline \multicolumn{3}{|l|}{ Day care in first 6 mo } \\
\hline Yes & 831 & 32.5 \\
\hline No & 1724 & 67.5 \\
\hline Unknown & 209 & \\
\hline \multicolumn{3}{|l|}{ Pets in first 6 mo } \\
\hline Yes & 1168 & 45.7 \\
\hline No & 1387 & 54.3 \\
\hline Unknown & 209 & \\
\hline \multicolumn{3}{|l|}{ Exposure to ETS in first $6 \mathrm{mo}$} \\
\hline Yes & 294 & 11.8 \\
\hline No & 2197 & 88.2 \\
\hline Unknown & 273 & \\
\hline \multicolumn{3}{|c|}{$\begin{array}{l}\text { Antibiotic exposure through breastfeeding in } \\
\text { first } 6 \text { mo }\end{array}$} \\
\hline Yes & 262 & 9.5 \\
\hline No & 2161 & 90.5 \\
\hline Unknown & 341 & \\
\hline \multicolumn{3}{|c|}{$\begin{array}{l}\text { Antibiotic exposure through oral medication } \\
\text { in first } 6 \text { mo }\end{array}$} \\
\hline Yes & 489 & 19.9 \\
\hline No & 1973 & 80.1 \\
\hline Unknown & 302 & \\
\hline \multicolumn{3}{|l|}{ Vaccinations in first 6 months } \\
\hline Standard vaccination schedule & 1969 & 77.4 \\
\hline Incomplete vaccination schedule ${ }^{b}$ & 393 & 15.4 \\
\hline Never vaccinated & 182 & 7.2 \\
\hline Unknown & 220 & \\
\hline \multicolumn{3}{|l|}{ Eczema in first year } \\
\hline No & 1953 & 77.0 \\
\hline Yes & 584 & 23.0 \\
\hline Unknown & 227 & \\
\hline \multicolumn{3}{|l|}{ Recurrent wheeze in first year } \\
\hline No & 2199 & 91.5 \\
\hline Yes & 203 & 8.5 \\
\hline Unknown & 362 & \\
\hline
\end{tabular}

a Data exclude missing respondents.

${ }^{b}$ This includes delayed schedule or alternative composition of vaccine. 
were eliminated from the regression models. Separate analyses of the conventional versus alternative subcohort or boys versus girls showed that the key findings were similar within these groups. Therefore, we combined all of the infants in the final analyses, adjusting for "subcohort." Results are presented as unadjusted and adjusted odds ratios (ORs) with corresponding 95\% confidence intervals (CIs).

\section{RESULTS}

In the present study, 3 children were excluded because of Down syndrome and 67 for prematurity (gestational age $<37$ weeks), resulting in 2764 participants. Of these, follow-up data on $\geq 1$ health outcome until age 1 year were available for $90.3 \%(n=2496)$, which was $89.1 \%$ $(n=2036)$ of the conventional and $95.8 \%(n=460)$ of the alternative subcohort.

About half of the infants had nonatopic parents; one third had 1 nonatopic older sibling, and 10\% had 1 atopic older sibling (Table 1). Most traditional risk factors were equally present in both subcohorts, but in the alternative subcohort, antibiotic exposure through medication was less present than in the conventional subcohort. By the age of 6 months, 1969 (77.4\%) of 2545 infants had been vaccinated according to a standard schedule, $393(15 \%)$ according to an incomplete schedule, and $182(7.2 \%)$ had never been vaccinated. Only $54.6 \%$ of the alternative compared with $95.5 \%$ of the conventional subcohort was vaccinated according to the standard schedule. In total, 584 of 2537 infants $(23.0 \%)$ were classified as having had eczema in the first year of life (this was $23.6 \%$ in the conventional and $20.4 \%$ in the alternative subcohort). Of these 584 infants with eczema, $483(83 \%)$ had no reported recurrent wheeze; $55(9 \%)$ also had reported recurrent wheeze, and for 46 infants, information on recurrent wheeze was unavailable. Recurrent wheeze was reported in 203 (8.5\%) of 2402 infants (this was $9.2 \%$ in the conventional and $5.1 \%$ in the alternative subcohort). Of these 203 infants with recurrent wheeze, 143 (70\%) had no eczema, and for 5 infants, information on eczema was unavailable. Of all infants with recurrent wheeze, $67 \%$ had used specific wheeze or asthma medication before 6 months old ( $\beta$ 2 -adrenergic or steroid inhalant therapy).
Compared with infants vaccinated according to the standard schedule, infants who were vaccinated according to incomplete schedules at age 6 months did not differ significantly in eczema risk (adjusted OR: 1.24; 95\% CI: 0.95-1.62; Table 2). This was also true for infants who had never been vaccinated at age 6 months compared with infants vaccinated according to the standard schedule (adjusted OR: 1.30; 95\% CI: 0.85-2.00). The risk for recurrent wheeze did not differ significantly in infants with incomplete vaccination schedules compared with infants with standard schedules (adjusted OR: 1.38; 95\% CI: 0.93-2.06). Again, this was also true for infants who had never been vaccinated (adjusted OR: 0.76; 95\% CI: 0.32-1.82).

To exclude potential reverse causation in the association between vaccinations and eczema or wheeze, we restricted our analyses to infants at risk for a first episode of eczema or recurrent wheeze after 6 months of age (by excluding infants who had eczema [ $n=447]$ or recurrent wheeze $[n=107]$ onset in the same period as vaccinations had been given, namely, the first 6 months). The ORs for eczema did not change much compared with those in Table 2 (adjusted OR for incomplete vaccination schedules: 1.52; 95\% CI: 0.95-2.43; adjusted OR for no vaccinations: 1.35 ; $95 \%$ CI: $0.58-$ 3.13). The same was true for the association between recurrent wheeze and having never been vaccinated (adjusted OR for no vaccinations: 0.98; 95\% CI: 0.342.87); but when done for incomplete vaccination schedule, the OR moved slightly toward the 1 (adjusted OR for incomplete vaccination schedules: 0.96; 95\% CI: 0.51$1.80)$. We tested the possibility of interaction between vaccination status and a parental or siblings' history of atopic manifestations in the multivariate analyses. None of these tests showed a statistically significant interaction $(P>.36)$.

Illness of the infant was only rarely the motive to refrain from all vaccinations in the first 6 months; this decision was more often based on beliefs with regard to a more natural development of the immune system, fear of adverse effects, and/or religion or life philosophy (Table 3).

TABLE 2 Associations Between Infant Vaccinations and Eczema and Recurrent Wheeze in the First Year

\begin{tabular}{|c|c|c|c|c|c|c|c|c|}
\hline \multirow[t]{2}{*}{ Vaccinations in First 6 mo } & \multicolumn{4}{|c|}{ Eczema $(N=2537)$} & \multicolumn{4}{|c|}{ Recurrent Wheeze $(N=2402)$} \\
\hline & $n / N^{a}$ & $\%$ & $\begin{array}{l}\text { Unadjusted OR } \\
\quad(95 \% \mathrm{CI})\end{array}$ & $\begin{array}{l}\text { Adjusted OR } \\
(95 \% \mathrm{Cl})^{\mathrm{b}}\end{array}$ & $n / N^{a}$ & $\%$ & $\begin{array}{l}\text { Unadjusted OR } \\
\quad(95 \% \mathrm{Cl})\end{array}$ & $\begin{array}{l}\text { Adjusted OR } \\
(95 \% \mathrm{Cl})^{\mathrm{b}}\end{array}$ \\
\hline Standard vaccination schedule & $428 / 1878$ & 22.8 & 1.00 (reference) & 1.00 (reference) & 149/1846 & 8.1 & 1.00 (reference) & 1.00 (reference) \\
\hline Incomplete vaccination schedulec & $101 / 377$ & 26.8 & $1.24(0.96-1.60)$ & $1.24(0.95-1.62)$ & 28/368 & 10.3 & $1.31(0.90-1.91)$ & $1.28(0.93-2.06)$ \\
\hline Never vaccinated & 43/177 & 24.3 & $1.09(0.76-1.56)$ & $1.30(0.85-2.00)$ & 7/172 & 4.1 & $0.48(0.22-1.05)$ & $0.76(0.32-1.82)$ \\
\hline
\end{tabular}




\begin{tabular}{|c|c|c|c|c|}
\hline \multirow[t]{2}{*}{ Motive } & \multicolumn{2}{|c|}{ Incomplete Vaccination Schedule ( $n=393)$} & \multicolumn{2}{|c|}{ No Vaccinations $(n=182)$} \\
\hline & $n$ & $\%$ & $n$ & $\%$ \\
\hline Infant's illness & 109 & 27.7 & 8 & 4.4 \\
\hline Preference for natural development of immune system & 93 & 23.7 & 161 & 88.5 \\
\hline Fear of adverse effects like allergy or other & 73 & 18.6 & 103 & 58.2 \\
\hline Doctor promotes restriction of vaccinations & 23 & 5.9 & 63 & 34.6 \\
\hline Religion or life philosophy & 23 & 5.9 & 99 & 54.4 \\
\hline Other & 132 & 33.6 & 54 & 29.7 \\
\hline
\end{tabular}

Percentages do not add to 100\% because of the possibility of checking $>1$ item.

\section{DISCUSSION}

In this prospective study in a cohort with a relatively large proportion of unvaccinated infants, we showed that compared with infants vaccinated according to the standard schedule, infants with incomplete schedules or who were never vaccinated against DPPT-Hib at age 6 months had no different risk for eczema and wheeze in the first year of life. Our study has the advantage of being population based, with relatively short intervals between subsequent follow-up questionnaires, which decreases the possibility of recall bias. The standard vaccination schedule in the Netherlands is not very complicated, and vaccination history may be reliably obtained using questionnaires. Nevertheless, we compared a subset of the parental responses to the information contained in medical charts and found that nearly all of the vaccination data based on medical charts to be reflected by the parental responses. We are fairly confident about the validity when parents report that the infant was not vaccinated. First, parents have most often well-expressed beliefs for not vaccinating; and second, the validation by the vaccination records showed 100\% agreement. By contrast, if parents reported that the infant was standard vaccinated, this was not always confirmed by the vaccination records. The vaccination records depend on reporting of each vaccination by the infant welfare center, and we cannot rule out that vaccinations were incompletely reported to the vaccination administration; however, because the validation was performed in the alternative subcohort where underreporting may be more prevalent than in the conventional subcohort, we think that misclassification is of minor effect on the results.

Follow-up rates were high, which would have limited potential bias with regard to baseline characteristics or outcomes. We showed that parents mainly choose to deviate from the standard vaccination schedule because of certain (philosophical) beliefs. This stresses that, at least in our study, motives to refrain from vaccinations are unlikely to be health related, which limits the possibility of confounding by contraindication or reverse causation. "Fear of side effects like allergy" was often the reason to refrain from all of the vaccinations, and one may argue that this is a potential risk for confounding by contraindication. This would, however, only be the case if fear of adverse effects was associated with an increased risk of eczema or wheeze by a family history of allergy, which was included as a potential confounder in all of our analyses. We showed previously that some prudent lifestyle characteristics, among others, vaccinations, differed between atopic and nonatopic families, depending on whether atopic manifestations were present in parents or older siblings. ${ }^{32}$ Therefore, we considered a parental and siblings' history of allergy as separate potential confounders in all of the analyses. "Infant's illness" was often a motive for alternative vaccination schedules but rarely for no vaccination, which also indicates that potential reverse causation is limited.

Several potential limitations merit consideration. Infant eczema and recurrent wheeze at age 1 year may be fairly unspecific for atopy. In individuals with an atopic constitution, the underlying mechanism of developing eczema is often dominated by an immunoglobulin $\mathrm{E}$ (IgE) antibody-associated reaction to specific allergens, justifying the term "atopic eczema." Specific IgE or total serum IgE levels are, however, only weakly associated with atopic symptoms like eczema and wheeze. ${ }^{33}$ Therefore, we evaluated clinical symptoms and used the term "eczema" instead of "atopic eczema." Our definitions of eczema and recurrent wheeze were based on questions adapted from International Study of Asthma and Allergies in Childhood questionnaires and included generally accepted characteristics, like a chronically relapsing course and an itchy rash (eczema) or recurrent symptoms (wheeze). The fact that the majority of wheeze complaints had been acknowledged by medical doctors (67\% of infants with reported recurrent wheeze had been using wheeze or asthma medication) may strengthen the validity of our measure. Second, parents who object to vaccinations could also have a different way of labeling atopic complaints. Differences in reporting eczema or wheeze symptoms could also have occurred between the conventional and alternative subcohort.

Our findings confirm the findings of some other authors, although they were observed in older children. Diphtheria, pertussis, tetanus (DPT)-vaccinated children were not afflicted more than nonvaccinated children 
with atopic disease at 5 years old ${ }^{23}$; wheezing illnesses $\leq 18$ months $^{22}$ and 42 months ${ }^{12}$; hay fever 25 ; asthma, allergy, and wheeze in children $<5$ years of age ${ }^{13}$; risk of asthma $\leq 6$ years old ${ }^{14,21}$; asthma, wheeze, and atopy age $\leq 6$ years ${ }^{24}$; and asthma or eczema $\leq 11$ years old. ${ }^{16} \mathrm{~A}$ case-control study including 7- to 8-year-old Dutch and German children showed no association between pertussis vaccination and respiratory symptoms. ${ }^{26}$ In these children, pertussis vaccine was coadministered with vaccination against DPT, but pertussis-unvaccinated children were not necessarily completely unvaccinated.

In contrast, authors of a Dutch retrospective study reported pertussis vaccination to be associated with lower risk of eczema in 6-year-old children. ${ }^{17}$ In this study, 39 of 44 infants classified as not vaccinated for pertussis had no vaccination at all, and pertussis-vaccinated infants were also DPT vaccinated. Therefore, the comparison made in this study would seem to reflect DPPT-vaccinated children versus completely unvaccinated children. A cross-sectional survey in children aged 3 to 18 years ${ }^{15}$ showed ever-eczema and current wheeze to be lower in partially vaccinated and completely unvaccinated children. However, because of its cross-sectional design, the results of this study should be interpreted with causation because of the possibility of reverse causation. In contrast, increased prevalence of eczema in DPPT-vaccinated children aged 0 to 5 years was found in a prospective cohort study in New Zealand with only 23 completely unvaccinated children. ${ }^{8}$ The authors of this study acknowledged that they had not been able to adjust simultaneously for all of the potential confounders because of the small numbers involved.

\section{CONCLUSION}

Our study shows that the risk of eczema or recurrent wheeze at the age of 1 year does not differ between infants with different vaccination statuses at age 6 months.

\section{ACKNOWLEDGMENTS}

We thank Petra Oomen (Dutch Vaccination Administration Office) for retrieval of vaccination records; Peter Luyten (medical student) for checking vaccination data; Edmond Schoorel, MD, for giving valuable advice; and all of the parents and infants who participated in this study.

\section{REFERENCES}

1. International Study of Asthma and Allergies in Childhood (ISAAC) Steering Committee. Worldwide variation in prevalence of symptoms of asthma, allergic rhinoconjunctivitis, and atopic eczema: ISAAC. Lancet. 1998;351:1225-1232

2. Illi S, von Mutius E, Lau S, et al. The natural course of atopic dermatitis from birth to age 7 years and the association with asthma. J Allergy Clin Immunol. 2004;113:925-931
3. Aaby P, Shaheen SO, Heyes CB, et al. Early BCG vaccination and reduction in atopy in Guinea-Bissau. Clin Exp Allergy. 2000;30:644-650

4. Anderson HR, Poloniecki JD, Strachan DP, et al. Immunization and symptoms of atopic disease in children: results from the International Study of Asthma and Allergies in Childhood. Am J Public Health. 2001;91:1126-1129

5. Floistrup H, Swartz J, Bergstrom A, et al. Allergic disease and sensitization in Steiner school children. J Allergy Clin Immunol. 2006;117:59-66

6. Odent $M$, Culpin E. Effect of immunisation status on asthma prevalence. Lancet. 2003;361:434

7. Odent MR, Culpin EE, Kimmel T. Pertussis vaccination and asthma: is there a link? JAMA. 1994;272:592-593

8. Kemp T, Pearce N, Fitzharris P, et al. Is infant immunization a risk factor for childhood asthma or allergy? Epidemiology. 1997; $8: 678-680$

9. Farooqi IS, Hopkin JM. Early childhood infection and atopic disorder. Thorax. 1998;53:927-932

10. Nilsson L, Kjellman NI, Bjorksten B. A randomized controlled trial of the effect of pertussis vaccines on atopic disease. Arch Pediatr Adolesc Med. 1998;152:734-738

11. Nilsson L, Kjellman NI, Bjorksten B. Allergic disease at the age of 7 years after pertussis vaccination in infancy: results from the follow-up of a randomized controlled trial of 3 vaccines. Arch Pediatr Adolesc Med. 2003;157:1184-1189

12. Henderson J, North K, Griffiths M, et al. Pertussis vaccination and wheezing illnesses in young children: prospective cohort study. BMJ. 1999;318:1173-1176

13. Hurwitz EL, Morgenstern H. Effects of diphtheria-tetanuspertussis or tetanus vaccination on allergies and allergy-related respiratory symptoms among children and adolescents in the United States. J Manipulative Physiol Ther. 2000;23:81-90

14. DeStefano F, Gu D, Kramarz P, et al. Childhood vaccinations and risk of asthma. Pediatr Infect Dis J. 2002;21:498-504

15. Enriquez R, Addington W, Davis F, et al. The relationship between vaccine refusal and self-report of atopic disease in children. J Allergy Clin Immunol. 2005;1 15:737-744

16. McKeever TM, Lewis SA, Smith $C$, et al. Vaccination and allergic disease: a birth cohort study. Am J Public Health. 2004; 94:985-989

17. Bernsen RM, de Jongste JC, van der Wouden JC. Lower risk of atopic disorders in whole cell pertussis-vaccinated children. Eur Respir J. 2003;22:962-964

18. Gruber C, Nilsson L, Bjorksten B. Do early childhood immunizations influence the development of atopy and do they cause allergic reactions? Pediatr Allergy Immunol. 2001;12: 296-311

19. Koppen S, De Groot R, Neijens HJ, et al. No epidemiological evidence for infant vaccinations to cause allergic disease. Vaccine. 2004;22:3375-3385

20. Rottem M, Shoenfeld Y. Vaccination and allergy. Curr Opin Otolaryngol Head Neck Surg. 2004;12:223-231

21. Maher JE, Mullooly JP, Drew L, et al. Infant vaccinations and childhood asthma among full-term infants. Pharmacoepidemiol Drug Safety. 2004;13:1-9

22. Mullooly JP, Pearson J, Drew L, et al. Wheezing lower respiratory disease and vaccination of full-term infants. Pharmacoepidemiol Drug Safety. 2002;11:21-30

23. Gruber C, Illi S, Lau S, et al. Transient suppression of atopy in early childhood is associated with high vaccination coverage. Pediatrics. 2003;111(3). Available at: www.pediatrics.org/cgi/ content/full/111/3/e282

24. Maitra A, Sherriff A, Griffiths M, et al. Pertussis vaccination in infancy and asthma or allergy in later childhood: birth cohort study. BMJ. 2004;328:925-926 
25. Bremner SA, Carey IM, DeWilde S, et al. Timing of routine immunisations and subsequent hay fever risk. Arch Dis Child. 2005;90:567-573

26. Mommers M, Weishoff Houben M, Swaen GM, et al. Infant immunization and the occurrence of atopic disease in Dutch and German children: a nested case-control study. Pediatr Pulmonol. 2004;38:329-334

27. Bernsen RM, van der Wouden JC. Re: no epidemiological evidence for infant vaccinations to cause allergic disease. Vaccine. 2005;23:1427

28. Kummeling I, Thijs C, Penders J, et al. Etiology of atopy in infancy: the KOALA Birth Cohort Study. Pediatr Allergy Immunol. 2005;16:679-684

29. Bastiaanssen JM, de Bie RA, Bastiaenen CH, et al. Etiology and prognosis of pregnancy-related pelvic girdle pain; design of a longitudinal study. BMC Public Health. 2005;5:1-8

30. Remes ST, Castro Rodriguez JA, Holberg CJ, et al. Dog exposure in infancy decreases the subsequent risk of frequent wheeze but not of atopy. J Allergy Clin Immunol. 2001;108: 509-515

31. Wright AL, Sherrill D, Holberg CJ, et al. Breast-feeding, maternal IgE, and total serum IgE in childhood. J Allergy Clin Immunol. 1999;104:589-594

32. Kummeling I, Thijs C, Stelma F, et al. Do parents with an atopic family history adopt a 'prudent' lifestyle for their infant? (KOALA Study). Clin Exp Allergy. 2006;36:489-494

33. Kusel MM, Holt PG, de Klerk N, et al. Support for 2 variants of eczema. J Allergy Clin Immunol. 2005;1 16:1067-1072 


\section{Diphtheria, Pertussis, Poliomyelitis, Tetanus, and Haemophilus influenzae Type b Vaccinations and Risk of Eczema and Recurrent Wheeze in the First Year of Life: The KOALA Birth Cohort Study}

Ischa Kummeling, Carel Thijs, Foekje Stelma, Macheld Huber, Piet A. van den Brandt and Pieter C. Dagnelie

Pediatrics 2007;119; $367-\mathrm{e} 373$

DOI: $10.1542 /$ peds. 2006-1479

\section{Updated Information \\ \& Services}

References

Subspecialty Collections

Permissions \& Licensing

Reprints including high-resolution figures, can be found at: http://www.pediatrics.org/cgi/content/full/119/2/e367

This article cites 32 articles, 9 of which you can access for free at:

http://www.pediatrics.org/cgi/content/full/119/2/e367\#BIBL

This article, along with others on similar topics, appears in the following collection(s):

Infectious Disease \& Immunity

http://www.pediatrics.org/cgi/collection/infectious_disease

Information about reproducing this article in parts (figures, tables) or in its entirety can be found online at:

http://www.pediatrics.org/misc/Permissions.shtml

Information about ordering reprints can be found online:

http://www.pediatrics.org/misc/reprints.shtml

\section{American Academy of Pediatrics}

